\title{
A QUESTÃO DA CIDADANIA NOS PRINCÍPIOS DA FILOSOFIA DO DIREITO DE HEGEL
}

\author{
Sergio Luis Rizzo Dela-Savia
}

\author{
Universidade Federal do Rio Grande do Norte
}

\begin{abstract}
Resumo: Este artigo pretende pôr em evidência a expressão conceitual que adquire a figura do cidadão no quadro da filosofia política hegeliana seguindo a exposição político-especulativa dos Princípios da Filosofia do Direito. Veremos que o movimento de figuração da cidadania - mediador das relações entre vida privada/vida pública, sociedade civil/Estado, direitos/deveres - evidencia um dos pontos fortes da ética hegeliana, a saber, que toda ordem política - é indissociavelmente ligada, ao mesmo tempo, aos costumes da sociedade e à atividade lúcida dos indivíduos. A partir dessa perspectiva de análise compreendemos melhor como os Princípios da Filosofia do Direito trazem à maturidade um elemento central do pensamento político moderno: a ideia de que a realização do bem comum repousa sobre a força e a estabilidade das instituições políticas.
\end{abstract}

Palavras-chave: Moralidade, Eticidade, Cidadania, Política, Instituição.

\begin{abstract}
This article intends to release the conceptual expression which the figure of the citizen within the framework of the Hegelian politic philosophy while following the politico-speculative talk of the Elements of the Philosophy of Right. We will see whereas the movement of figuration of the citizenship mediator of the ratios private life/public life, civil society/State, rights/duties - clarifies one of strong points of Hegelian ethics, i.e., that all the political command are indossociably connected, at the same time, with customs of the society and the lucid activity of the individuals. From this perspective of analysis we understood better as the Elements of the Philosophy of Right carries to its maturity an central element of the modern political thought: that the realization of the community property rests on the force and the stability of the political institutions.
\end{abstract}

Keywords: Morality, Ethnicity, Citizenship, Politics, Institution.

Na conclusão de sua "petite éthique", constituída pelo conjunto dos sétimo, oitavo e nono estudos apresentados na obra Soi-même comme un autre, Ricœur situa o problema do conflito na vida prática. Particularmente, a ideia que preside as considerações que o filósofo apresenta no Interlídio da obra é a seguinte: "Na falta de produzir um ensino direto e unívoco, a sabedoria trágica devolve a sabedoria prática à prova do único julgamento moral em situação" (1991, p.283). A exemplo de Hegel, Ricœur apoiará suas análises no Antígona, de Sófocles. De suas observações vale, a meu ver, sublinhar as consequências de um retorno do trágico para o agir político. Com efeito, no nível da práxis política, o retorno do trágico pode ter um sentido perfeitamente antidemocrático, no sentindo de que a tragédia revela a dimensão não controlável 
de nossos engajamentos práticos, bem como seu direito primordial sobre a ordem política e mesmo contra esta.

No que diz ao pensamento político hegeliano, a preocupação de Ricœur foi pensar uma alternativa à aparente transcendência assumida pela noção de Sittlichkeit, no plano da Filosofia do Direito, em relação aos recursos de uma moralidade em situação (cf. ibid., p. 300). Nesse sentido, a oposição hegeliana entre Sittlichkeit e Moralität parece-lhe desprovida de legitimidade e revela-se mesmo prejudicial se pensarmos na realização da justiça fora dos domínios de uma filosofia do Geist. Essa "superioridade" das potências éticas, que abriga a dimensão da Sittlichkeit hegeliana, é uma dificuldade menos patente que o seu corolário efetivo, nesse caso, o Estado. Com efeito, Ricœur tem razão de sublinhar que, para nós que testemunhamos os fenômenos totalitários do século XX, seria temerário atribuir uma tal centralidade à esfera do Estado. No entanto, devemos entender que, no nível da realização da liberdade e da justiça, Hegel pretendeu defender as instituições éticas do assalto da particularidade subjetiva, do desejo da vontade individual em querer prevalecer sobre o bem público. O que confere à Sittlichkeit sua posição singular no plano da Filosofia do Direito é a possibilidade mesma de se constituir uma relação substancial entre os indivíduos e as instituições que encarnam aquelas potências éticas na sociedade. Penso que a solução para o problema da falência ética de um Estado não é o retorno à oposição Sittlichkeit/Moralität, visando-se, por esse meio, restabelecer àquele uma dignidade ora eclipsada pela magnitude da figura do Estado ${ }^{1}$ mas, antes, o de pensarmos um sentido renovado da Sittlichkeit que possa escapar à aparente hipertrofia que a figura do Estado recebe no pensamento político hegeliano. É nesse sentido que podemos encontrar a boa via que nos permitiria pensar a eticidade sem o efeito de um superdimensionamento da esfera estatal. Essa boa via é evocada pelo próprio Ricœur nesses termos:

A melhor maneira de desmistificar o Estado hegeliano e, por esse próprio meio, liberar seus recursos inesgotáveis no plano da filosofia política é interrogar a própria prática política e examinar as formas específicas que reveste aí o trágico da ação (ibid., p.300, grifo do autor).

É no nível da constituição de um espaço público e do fortalecimento/alteração das instituições - sem eliminar a incerteza e o conflito inerente ao campo da ação política como tal - que "a Sittlichkeit

\footnotetext{
${ }^{1}$ A esse respeito o autor escrevia: "Quando o espírito de um povo é pervertido a ponto de alimentar uma Sittlichkeit homicida, é finalmente na consciência moral de um pequeno número de indivíduos, inacessíveis ao medo e à corrupção, que se refugia o espírito que desertou das instituições tornadas criminais", ibid., p.300.
} 
hegeliana - que também se enraíza nos Sitten, nos 'costumes' - mostra-se equivalente da phronèsis de Aristóteles: uma phronèsis para diversos ou, antes, pública, como o próprio debate" (ibid., p. 306). Assim, a eticidade, na medida em que globaliza os elementos do ethos (as leis da sociedade, as regras práticas, os princípios morais etc.) nos diversos campos onde vivem e agem os indivíduos (a vida familiar, as relações no mundo do trabalho e na vida social, a intervenção nas questões de interesse coletivo etc.), é o terreno de uma realização compartilhada da phronèsis, uma sabedoria prática plural que nasce da mediação dos indivíduos através da sua participação no espaço público. $\mathrm{Na}$ compreensão de Ricœur: "a Sittlichkeit aí repete a phronèsis, uma vez que a Sittlichkeit 'mediatiza' [médiatise] a phronèsis" (ibid., p. 339). Trata-se de vermos, então, como a eticidade oferece-se como campo do autêntico exercício da cidadania.

\section{Disposição moral e subjetividade política}

Que sentido podemos dar às palavras com as quais Hegel abre sua exposição sobre o Estado: "O Estado é a efetividade da ideia ética"? J-F Kervégan propõe uma pista de leitura:

O Estado é uma realidade ética: isto implica que ele não pode ser concebido como uma simples estrutura institucional, mas combina as dimensões da subjetividade e da objetividade que a consciência moderna opõe espontaneamente. [...] Mas o Estado é mais que a realidade da ética: ele é sua efetividade, o que quer dizer a racionalidade realizada (apud HEGEL, 1998, p.79, grifo do autor).

A ideia ética expressa, nesse sentido, um dos eixos da filosofia política hegeliana, a saber, a articulação entre a singularidade, isto é, o cidadão, com as determinações que lhe estão próprias (consciência de si, vida comunitária [família e sociedade civil], trabalho, interesses privados), e a universalidade, nesse caso, as instituições que compreendem a forma histórica que alcança o Estado e que se configura como a ordem ética elaborada pelo trabalho dos indivíduos e objetivada nas instituições públicas.

Hegel pretende que uma tal síntese entre singularidade e universalidade ética, entre a vontade dos indivíduos e as instituições públicas produza, de modo substancial, o equilíbrio entre a autoafirmação da própria liberdade e a existência de uma ordem política que respalde, anime e oriente o exercício dessa liberdade é o que torna o Estado aquela "efetividade da Ideia ética", como argumenta Weil:

O Estado é livre se o cidadão razoável pode encontrar nele a satisfação de seus desejos e interesses razoáveis, interesses que, enquanto ser pensante, ele pode justificar perante si mesmo, se o cidadão reconhece nas leis do Estado a 
expressão dos sentimentos e da tradição que o guiaram (ainda que disso ele não saiba), se essas leis não são somente justas do ponto de vista de um tirano esclarecido, mas se elas podem e devem ser reconhecidas como tais por todos aqueles que querem a justiça, por todos aqueles que buscam sua liberação de todo dado imediato (1966, p.54).

Em virtude dessa síntese do universal e do particular, a concepção de Estado formulada na Filosofia do Direito apresenta-se como a consumação dessas determinações postas pelas figuras da família e da sociedade civil. Isso quer dizer que, no Estado, o indivíduo tem o reconhecimento universal de sua pessoa, a proteção de sua propriedade, a preservação de seu bem-estar, a promoção de seus interesses e, simultaneamente, a consciência de uma vida comunitária e da realização de sua essência substancial nela (HEGEL, 2010, \$261). Desse modo, a solidez das instituições, a racionalidade da Constituição, a unidade e a coesão internas do Estado têm seu fundamento nessa substancialidade ética, enquanto ela é, de uma lado, um saber, a autoconsciência dos cidadãos que, enquanto tais, se sabem livres, e, de outro, um mundo objetivo, real, no qual a rą̧ão dos indivíduos veio a se cristalizar em leis e instituições. Por isso, o substancial ético, como o saber e o querer universais da autoconsciência subjetiva, torna-se para o cidadão uma necessidade, e o interesse pelos assuntos éticos vem a ser nele sua disposição-de-espirito política (politsche Gesinnung, cf. HEGEL, 2010, \$267-268).

As instituições, leis e poderes do Estado têm, no agir dos cidadãos no respeito pela coisa pública, no seu interesse e participação nas questões que dizem respeito à vida de toda a comunidade, na sua intervenção nos rumos políticos da nação, expostos e definidos pelo governo - seu momento atualizador. Nessa intercessão entre os poderes do Estado e o exercício da cidadania, "o universal se produz continuamente e de modo necessário" (HEGEL, 2010, \269, grifo do autor). Assim, os justos interesses do cidadão - para distinguir de seus interesses privados - que, em última instância, são a mola mestra de seu engajamento na vida orgânica da comunidade ética, devem não apenas ser "permitidos" pelo poder do Estado, mas reconhecidos na sua legitimidade e assumidos, em sua essência, pela vontade ética desse Estado. Se o conjunto das leis de um Estado afirma esse anseio ético dos cidadãos, não será nenhum problema afirmarmos, com Hegel, que a observância às leis seja uma obrigação do cidadão, e seja, enfim, o que o define como tal. O que quer o cidadão? Uma vida racional para si e para os seus compatriotas, em outras palavras, ele quer a realidade de sua liberdade e, nessa medida, a universalização desse princípio. Entretanto, os interesses egoístas de indivíduos e grupos, justamente porque estão em desacordo com a racionalidade e o universal presentes na lei do Estado, se forem eles as forças a valer no domínio 
político, enfraquecerão a moral viva dessa comunidade, até ao limite da dissolução do organismo ético².

\section{A cidadania como mediação institucional da liberdade}

É preciso considerar, em um estudo acerca do papel do cidadão na atualização da vida ética, a repercussão fortemente política que adquire a concepção hegeliana da sociedade civil que, como tal, se caracteriza por ser, precisamente, uma ordem social não diretamente política. Assim, fazendo a mediação entre a sociedade civil e o Estado, as corporações (cf. HEGEL, 2010, \$249) realizam, no plano ético da Filosofia do Direito, a síntese entre as aspirações dos indivíduos que, no que diz respeito às suas competências profissionais específicas se dirigem para os seus negócios privados, bem como para a satisfação dos seus interesses e bem-estar próprios, e a consciência de seu ser-em-comum, de sua integração em uma vida comunitária assegurada pela universalidade da lei $^{3}$.

Ordenada e disposta mecanicamente como sistema para o atendimento das necessidades e como espaço de interação subjetiva, a sociedade civil-burguesa comporta, de modo ambivalente, o alto valor da sociabilidade e da complementaridade dos interesses e o risco da marginalidade, da exclusão e da desigualdade. Mas, igualmente, as figuras do burguês e do cidadão são diferentes na medida em que, ao cidadão, abre-se um campo de atividades cujo sentido e valor transcendem a disposição natural do indivíduo votada à consecução de interesses privados.

\section{1- Os poderes do Estado}

A necessidade de superação dialética dos impasses próprios à sociedade civil conduz, no plano da Filosofia do Direito, à conceitualização do Estado. Porém, a unidade do Estado não é formada pela divisão dos poderes que o constitui - pelo que Hegel distancia-se de Montesquieu em sua crítica ao sistema democrático, naquilo em que essa unidade substancial reduz-se à

\footnotetext{
${ }^{2}$ A propósito, comenta Weil, com muito acerto: "o cidadão do Estado constitucional conhece a sua liberdade e as suas obrigações, a primeira delas sendo a de exprimir suas preferências no que concerne aos projetos de ação que interessam ao todo do Estado, a segunda, de submeter-se à decisão tomada e manter, no que lhe compete, a unidade do Estado" (1990, p.262).

${ }^{3}$ Mas Hegel sabia muito bem que a sociedade civil era incapaz de garantir o igual direito ao exercício da liberdade. É relevante, a propósito, o comentário crítico de H. Arendt sobre ilusão da economia liberal de que a garantia da posse privada bastaria para salvaguardar as liberdades individuais: "Numa sociedade de empregados, estas liberdades somente se mantêm enquanto são garantidas pelo Estado, e agora são constantemente ameaçadas, de modo nenhum pelo Estado, mas pela sociedade, que distribui os empregos e fixa as partes de apropriação individual", 1983, p. 109. Caberá, então, à esfera política - ao Estado propriamente - fazê-lo.
} 
abstração numérica dos cidadãos. Essa é, de resto, uma crítica que Hegel efetua a respeito de todos os regimes, se o que se destaca é tão somente a diferença quantitativa ${ }^{4}$. O que Hegel não concede é que "o princípio da vontade individual seja considerado único fundamento da liberdade política" (HEGEL, 1995c, p.43), com o que se anularia a substancialidade efetivada na Constituição, e toda a organização política se veria reduzida a um "centro desprovido de vontade" que, para todos os assuntos, precisaria ter garantido, em votos, o aval de cada indivíduo. O dever ético cabível ao cidadão em nada limita a liberdade subjetiva mas, antes, mostra-se justamente como aquilo que limita a própria liberdade naquilo que ela tem como arbitrário de uma vontade estritamente individuaF. Fundamentalmente, os engajamentos práticos do sujeito decorrem do fato de que ele reconhece, admite para si, faz suas as leis que ele decide livremente partilhar com outros. Esse é o sentido moderno de autonomia e que é um sentido eminentemente político, e não primeiramente moral. O cumprimento do dever adquire, então, o sentido de uma atividade mediadora que os cidadãos devem levar a efeito no processo de efetivação das potências éticas, visto que "as leis e os princípios não vivem nem se impõem imediatamente por si mesmos" (HEGEL, 1979, p.104). Sendo, portanto, a substancialidade ética o que garante aquela identidade entre a vontade do sujeito e as forças éticas, é nela que encontraremos o fundamento conceitual da cidadania. Faz-se mister, então, considerá-la nas suas determinações principais.

Para ser adequadamente compreendida a filosofia política hegeliana e a possibilidade mesma de pensarmos nela uma atuação cidadã efetiva - deve ser pensada a partir de uma dinâmica de institucionalização do domínio público na e pela mediação sócio-política do poder. Temos isso claramente delineado na estruturação das instituições representativas do Estado ${ }^{6}$. O caráter orgânico da articulação entre os poderes do Estado e as organizações civis impedem que os interesses privados pulverizem o corpo social e transformem, assim, o povo em massa, isto é, torne a nação um ajuntamento informe de indivíduos, um atomismo inorgânico. Se assim fosse, não só as classes sociais não lograriam "uma atividade eficaz e uma significaşão políticas"

\footnotetext{
4 Ver a longa observação do $\$ 278$ e, mais particularmente, aquelas dos $\S \S 279$ e 308.

${ }^{5}$ Em um curso sobre Filosofia da História, Hegel assinala o equívoco de se tomar a limitação do arbítrio da vontade por limitação da própria vontade: "O eterno mal-entendido provém, portanto, do conceito puramente formal, subjetivo, abstrato que se faz da liberdade considerada independentemente das tarefas e dos objetos que lhe são próprios. Assim, se confunde a liberdade com os instintos, os desejos, as paixões, o capricho e 0 arbitrário dos indivíduos particulares e tomamos sua limitação por uma limitação da liberdade" (1965, p.143).

6 Cf. Filosofia do Direito, §§272-313.
} 
como também o universal ético se enfraqueceria (HEGEL, 2010, \$303, grifo do autor).

Para Hegel é o princípio da unicidade e indivisibilidade o que baseará a ideia de soberania na Filosofia do Direito (cf. HEGEL, \$\$278-280). Nesse sentido, não se pode tomar a divisão interna do Estado como uma mera articulação partes extra partes entre os poderes que o constituem. O fundamental, nesse ponto, é a compreensão daquilo que confere ao poder do Estado sua unidade, ao mesmo tempo em que nele esteja presente uma diferença entre instâncias que guardam, cada uma, uma função própria. Nesse sentido, Hegel pensa uma unidade que se autodiferencia em esferas específicas, e isto quer dizer três coisas, especialmente: 1) nenhum poder representa o Estado na sua totalidade, mas, por sua diferenciação necessária, correspondem a domínios próprios de competência; 2) não há, rigorosamente, separação dos poderes, visto que, para Hegel, os poderes não se encontram em uma independência absoluta face à totalidade ética; e, por decorrência desses aspectos, 3) se um dos poderes se impõe ou tenta prevalecer sobre os outros, isto evidencia a inexistência desta unidade substancial e, nesse caso, este Estado não logra realizar a Ideia ética ${ }^{7}$. Esta unidade substancial que é o Estado conterá, na Filosofia do Direito, três funções: o poder legislativo, o poder governamental e o poder do principe ou monarquia constitucional. Embora, em sua análise, Hegel inverta essa ordem, ela apresenta um ordenamento lógico significativo, segundo o silogismo U-P-S (Universal-Particular-Singular). Nesse plano, cada um dos poderes do Estado encarna uma função, simultaneamente lógica e política, no processo de mediação que estrutura e organiza as instituições políticas. Assim, o poder legislativo representa o momento da universalidade pela mediação dos interesses gerais; o poder governamental figura, por sua vez, o particular do saber técnico aplicado à gestão pública; por fim, o poder do príncipe exprime o singular da decisão suprema. Se ao legislativo concernem as tarefas do Estado que têm um conteúdo universal (cf. HEGEL, \$298), o trabalho do poder legislativo, na concepção hegeliana, não está entregue exclusivamente uma câmara de deputados. $\mathrm{O}$ trabalho do legislativo é coadjuvado pelo poder do monarca, - visto que lhe cabe a decisão - e pelo governo - "momento consultivo", posto que a ele pertence "o conhecimento concreto e a visão geral do todo" (cf. HEGEL, 2010, \$300). Deve ser ressaltado, uma vez mais, o aspecto dialético implicado nessa mediação, cada poder exerce uma forma de mediação relativamente aos outros dois poderes ao mesmo tempo em cada um preserve sua especificidade em relação à totalidade política. Esse aspecto lógico

7 Ver análise de Weil acerca destes pontos, cf. La philosophie politique de Hegel, 1992, p.293-294. 
é precisamente expresso no parágrafo 302 da Filosofia do Direito: "Isso pertence aos discernimentos lógicos mais importantes de que um momento determinado, enquanto se mantém na oposição, tem a posição de um extremo, por causa disso, deixa de sê-lo e é um momento orgânico, que é, ao mesmo tempo, meio termo" (HEGEL, 2010, grifo do autor). É precisamente essa dinâmica dialética o que nos faculta a inteligência de uma relação entre os poderes internos do Estado na qual cada um, guardada sua singularidade, exerce a função lógica de meio termo, isto é, cada um dos poderes exerce um papel mediador no seio da organicidade estatal. Com isso, a oposição entre essas instâncias não é efetiva, ou sua oposição é mera "aparência".

Se o Estado moderno não é um aglomerado abstrato de indivíduos, mas uma unidade ética concreta que se efetiva pela singularização do universal e universalização do singular -, o sufrágio universal manifesta, então, a inconsistência racional do sistema democrático que faz crer, enganosamente, que cada membro do Estado, tão somente em função desse status - em verdade, quase tão natural quanto a pertença do indivíduo a uma determinada família -, pelo voto, intervém pessoalmente nos assuntos públicos e põe, na mesa das decisões políticas nacionais, seu saber e sua vontade individual.

No entanto, a representação política do indivíduo, delegada aos deputados por meio das organizações da sociedade civil, não significa uma renúncia pessoal à autodeterminação e ao livre-querer de cada um. Isto por que essa assembléia dos cidadãos não constitui uma simples transferência do poder político de vários particulares (os cidadãos) a poucos particulares (os deputados). Se o cidadão não ascende à consciência do universal naturalmente, apenas porque é membro do Estado, mas na medida em que se descobre membro de uma comunidade - da família, da sociedade e do Estado - e, então, sabe-se co-responsável pela construção de um mundo no qual a razão, vale dizer, a liberdade, seja preservada do assalto e da manipulação dos interesses egoístas de alguns por intermédio da formação do direito e da Constituição, então a representação política não pode fincar raiz na determinação individual, mas antes na vontade racional constituída organicamente, isto é, pela conjunção entre a vontade individual (e seus interesses) e as organizações que fazem eco à suas preocupações e a expressam como vontade comum. O Estado concreto não se faz pela determinação de

8 Cf. cf. HEGEL, 2010, §302. Essa relação silogística entre os poderes do Estado traduz, como momento político, momentos lógicos meramente abstratos, como nota Jean-Philippe Deranty: "cada poder é uma forma de mediação entre os dois outros poderes, uma função política específica contendo também os dois outros. Mas cada poder é também um ponto de vista particular sobre a totalidade política" "Le parlement hégélien", in: KERVÉGAN, Jean-François, MARMASSE, Gilles [dir.], Hegel, penseur du droit, 2004, p.249). 
um "eu quero" individual e exclusivo, mas ele "é o todo articulado em seus círculos particulares; o membro do Estado é um membro de tal estamento; apenas nessa sua determinação objetiva pode ser tomado em consideração no Estado" (HEGEL, 2010, §308, grifo do autor).

\section{A cidadania e a questão do reconhecimento}

Encontramos nessa identidade entre a consciência ético-política dos cidadãos e a estruturação dos poderes do Estado - se esse Estado realiza a ideia moderna de Estado - o ponto forte da filosofia política hegeliana, que atesta o campo da ação política como espaço por excelência do reconhecimento do subjetividade política, simultaneamente, membro da família, da sociedade civil e do Estado e cuja compreensão encontra no parágrafo 260 sua formulação peremptória:

O Estado é a efetividade da liberdade concreta; mas a liberdade concreta consiste em que a singularidade da pessoa e seus interesses particulares tenham tanto seu desenvolvimento completo e o reconbecimento de seu direito para si (no sistema da família e da sociedade civil-burguesa), como, em parte, passem por si mesmos ao interesse do universal, em parte, com seu saber e seu querer, reconheçam-no como seu próprio espírito substancial e são ativos para ele como seu fim último, isso de modo que nem o universal valha e possa ser consumado sem o interesse, o saber e o querer particulares, nem os indivíduos vivam meramente para esses últimos, enquanto pessoas privadas, sem os querer, ao mesmo tempo, no e para o universal e sem que tenham uma atividade eficaz consciente desse fim. O princípio dos Estados modernos tem esse vigor e essa profundidade prodigiosos de deixar o princípio da subjetividade completar-se até o extremo autônomo da particularidade pessoal e, ao mesmo tempo, o reconduz para a unidade substancial e, assim, mantém essa nele mesmo (HEGEL, 2010, grifo do autor).

Em uma perspectiva inteiramente inovadora para seu tempo, Hegel fornece à teoria do Estado uma concepção de representação política na qual as instituições representativas adquirem uma função de mediação (cf. HEGEL, 2010, \$302), função esta que efetiva-se em relações múltiplas envolvendo todos os atores políticos (entre monarca e cidadãos, entre Estado e sociedade-civil etc). Para a salutar efetivação dessa dinâmica é fundamental que o povo ascenda ao universal ético, vale dizer, torne-se o que ele é: um povo, não uma massa. Kervégan nota, com acerto:

Se o povo não sabe o que ele quer, é que ele não é imediatamente o que ele é: um povo, não uma multidão. A representação, que dá corpo, pensamento e voz a essa "massa informe", permite ao povo ascender ao ser político, superar sua diversidade contraditória, sua particularidade retorcida sobre si mesma. Ao mesmo tempo, a representação aparece como a condição decisiva da soberania" (2007, p.280). 
Vale precisar, nesse contexto, o caráter eminentemente político que adquire aqui a noção de reconbecimento (Anerkennung), distinto da configuração em que esta é pensada no âmbito da Fenomenologia do Espirito, tal como Hegel a modula na dialética do senhor e do escravo. Com efeito, no nível psicológico das relações intersubjetivas a dialética do senhor e do escravo simboliza o processo por meio do qual o sujeito conquista a emancipação de sua personalidade, o inteiro desenvolvimento de sua individualidade. A consciência que assume o risco de arrancar-se de sua fixação biológica (condição de todo vivente) e que afirma o eu ideal como correspondendo à sua essência tal é, propriamente, a figura do mestre: é a consciência poder escapar à escravidão da vida. Inversamente, a escravidão não é outra coisa que a consciência de si que afirma sua ligação/dependência ao corpo e à vida. $\mathrm{O}$ que vemos, pois, se desenrolar na dialética do senhor e do escravo é, com efeito, uma figuração trágica das relações humanas. Essa dimensão trágica é conferida, desde o princípio, pelo irresistível impulso em direção ao outro que conduz os dois sujeitos ao afrontamento inevitável, pois o que se decide aqui é uma luta, e luta de puro prestígio. Nesse face a face se instaura, de imediato, uma tensão cujo limite expõe o homem ele próprio. Ser si-mesmo pela mediação de uma outra consciência, isto é, ser reconbecido, pressupõe o sacrifício da posição de partida na qual se está instalado quando do início do afrontamento: esse reconhecimento exige o sacrifício dessa vida aî . Por isso é que, nesse afrontamento, haverá um que sairá vencedor, por ter aceitado o risco de perder sua vida a fim de afirmar-se, e haverá um outro que sairá capitulado, por ter preferido conservar sua vida tal qual e ter renunciado ao combate lá onde a morte lhe parecia insuportável. No plano da Filosofia do Direito o reconhecimento é situado no nível das relações sociais e políticas e, aqui, o reconbecimento implica necessariamente sua mediação pelas instituições permitindo, desse modo, a formação/integração do sujeito ao todo da vida ética.

É nessa perspectiva que intervém a reflexão de Axel Honneth sobre a luta pelo reconhecimento e sua aplicação no contexto da Filosofia do Direito, a qual ocasionou vivo debate entre comentadores de Hegel. Com efeito, Honneth, em seu livro As patologias da liberdade: uma reatualização da filosofia do direito de Hegel (2008) aprofunda sua leitura do pensamento político hegeliano iniciadas em Luta por reconhecimento (2010), obra na qual já havia mobilizado recursos da

${ }_{9}^{9}$ As palavras de Hegel sintetizam a natureza do engajamento dos adversários: "É somente pelo risco da sua vida que se conserva a liberdade, que se prova que a essência da consciência de si não é o ser, não é o modo imediato no qual a consciência de si surge, não é seu submergir-se na expansão da vida", (1941, p.159). 
filosofia do Espírito de Hegel, relativa aos escritos de Iena - portanto, anteriores à Fenomenologia do Espírito e à Ciência da Lógica -, a fim de esboçar uma teoria da intersubjetivista do reconhecimento, enxergando na Filosofia do Direito de Hegel um tratado de individualização social. Assim, Honneth lê as três esferas que compõem a Sittlischkeit (família, sociedade civil e Estado) como campos nos quais desenrola-se progressivamente o processo de socialização do indivíduo através da aprendizagem de "jogos de linguagem" normativos específicos de cada uma dessas esferas (necessidade, interesse, honra) e pela instauração de múltiplos processos de reconhecimento recíprocos. Mesmo que seja legítima a tentativa de uma reinterpretação dos primeiros escritos de Hegel como um modelo de justiça alternativo às teorias normativas, as reflexões de Honneth o distanciam nitidamente do pensamento político hegeliano, cujas premissas assentam a questão do reconhecimento numa perspectiva marcadamente institucional. Olivier Tinland, sugerindo prudência quanto às conclusões que Honneth tira ao evidenciar uma tensão existente entre teoria dos costumes e institucionalismo na obra de Hegel, assinala não ser evidente:

Que as derivas atuais da desregulamentação neoliberal invoquem em seu favor
um anti-institucionalismo político: Hegel é o primeiro a sublinhar que a
independência de que gozam os indivíduos na sociedade civil somente é possível
porque o Estado definiu previamente as condições institucionais que permitem
regulamentar e conter a tendência anárquica das relações socio-econômicas.
(2008, p.5).

Honneth parece substituir, ao formalismo da autonomia dos indivíduos fundamentada pela moral kantiana - que acaba por negligenciar os enquadramentos sociais nos quais (e a partir dos quais) efetiva-se a liberdade do sujeito moderno - a horizontalidade das relações intersubjetivas negligenciando, por seu turno, a articulação positiva entre "a socialidade informal da vida ética e a socialidade formal das instituições do Estado" (TINLAND, 2008, p.5).

Contudo, em uma obra mais recente, $O$ direito da liberdade: esboço de uma eticidade democrática (a edição alemã é de 2011) ${ }^{10}$ Honneth, reafirmando sua filiação ao "modelo da filosofia do direito hegeliana" (2015, p.11), assume uma perspectiva mais diretamente assentada na noção central da teoria hegeliana do espírito objetivo, aquela da Sittlichkeit. A ambição do autor é a de fundar uma teoria da justiça a partir de uma análise da sociedade que possa escapar à "fixação de princípios puramente normativos" (2015, p.15), tal como a que se verifica na corrente normativista dominante neste campo, centrada no

10 Utilizo para este artigo a edição francesa Le droit de la liberté: esquisse d'une éthicité démocratique. Paris: Gallimard, 2015. 
pensamento kantiano. O que está em questão é, portanto, uma radical mudança de perspectiva metodológica. Honneth argumenta que uma teoria da justiça não se sustenta se ela apresenta seus princípios por meio de um procedimento metodológico dedutivista, construtivo, prescrevendo o que é justo e bom para a sociedade, como é o caso das teorias convencionais que ele nomeia "kantianas". Ora, toda sociedade produz constantemente as regras práticas que a estruturam, as quais estão na base de todo o tecido das relações sociais e institucionais. É nesse sentido que Honneth irá se inscrever no horizonte da Sittlichkeit hegeliana: "Toda sociedade", afirma, "encarna, em uma certa medida, o espírito objetivo: suas instituições, suas práticas e rotinas sociais refletem as convicções normativas partilhadas pelos membros desta sociedade a propósito dos objetivos de suas relações de cooperação" (2105, p.20-21). Com efeito, as análises que Hegel desenvolve na Filosofia do Direito do que pode ser determinado, em uma sociedade, como justo e bom somente se mostram bem fundados se são medidos à luz dos ideais efetivamente institucionalizados nesta sociedade. Assim, os usos e costumes - numa palavra, o ethos da sociedade - prefiguram, concretamente, o horizonte - social e institucional - de vivência dos valores substanciais capazes de orientar os engajamentos práticos dos indivíduos. Nessa perspectiva, na descrição de sua démarche metodológica Honneth assevera, com Hegel, que "as únicas formas de vida sociais podendo ser consideradas certamente como 'éticas' [sittlich] são aquelas que encarnam um valor universal, no sentido em que as práticas apropriadas à sua concretização já adotaram uma forma na sociedade" (2015, p.25, grifo do autor). Parece-nos, pois, que a "reconstrução normativa" proposta pelo autor, nessa obra, abre um campo fecundo para uma atualização da teoria da justiça, assim como da filosofia política de inspiração genuinamente hegelianas, mesmo se a manifesta assimilação entre uma estrutura intersubjetiva da liberdade - no sentido de uma ordem normativa do reconhecimento - e a concepção hegeliana de uma mediação institucional da liberdade continue a fazer objeto de um debate crítico, como vimos anteriormente ${ }^{11}$.

11 Honneth afirma, a propósito: "Sublinhar a estrutura intersubjetiva da liberdade permite tomar consciência da necessidade de instituições operadoras de mediação, instituições cuja função consiste em fazer que os sujeitos sejam informados previamente da interdependência de seus objetivos. A ideia hegeliana segundo a qual a liberdade individual deve ser 'objetiva' significa, pois, simplesmente, que instituições apropriadas, concretamente, as instituições do reconhecimento mútuo, são necessárias quando se trata de promover a realização concreta da liberdade reflexiva do individuo" (2015, p.106. Grifo do autor). 


\section{Considerações finais}

O desenvolvimento dialético e político da Filosofia do Direito possibilitanos considerar que a figura do cidadão constrói-se a partir das múltiplas experiências constitutivas do sujeito histórico. O cidadão é o sujeito que, em verdade, no seu agir, percorreu (dialeticamente) os momentos de vivência do ethos: como singular ético imediato (membro da família), como singular que existe para-si e age em vista de seus interesses particulares (indivíduo social) e que, a partir de uma integração dialética (Aufbebung) desses momentos, reconhece-se partícipe de uma esfera universal que ultrapassa aquela de um campo de reconhecimento intersubjetivo ${ }^{12}$. O Estado é, então, o universal genérico que se desdobra (dialeticamente) nos momentos da família e da sociedade civil, que concretizam, cada qual, uma vivência do universal e que têm seu cumprimento necessário (Notwendigkeit) no Estado, enquanto universalidade que é sabida (a substância consciente de si). $\mathrm{Na}$ família, a substância ética revela-se como universal imediato - o espírito na sua determinação natural (HEGEL, 2010, \$157), ou o "espírito que-sente" (1995, §518); na sociedade civil, a substância ética é a racionalidade que ordena o mundo comum - a produção da vida material coletiva como sistema (HEGEL, 2010, \$183) -, enquanto espaço de realização das capacidades individuais para o atendimento das necessidades (HEGEL, 2010 \$189) (Bedürfnisse).

De sua parte, o indivíduo somente pode realizar-se plenamente como ser social tomando parte nos assuntos relativos à vida em comum. Dessa forma, Estado e cidadão realizam-se conceitualmente por meio de uma correlação dialética que faz emergir o ser que cada qual é (existência imediata) e o ser que cada qual alcança na mediação com o outro (essência) ${ }^{13}$. De uma parte, pode-se tomar o Estado na sua fenomenalidade. Ele é este Estado nacional, reconhecido na sua individualidade e soberania perante outros Estados e constituído por um aparelho jurídico e institucional determinado. Contudo, sua significação racional - conceitual - não está posta nele objetivamente senão pela mediação com a atividade do singular. Este (o cidadão), por sua vez, é um sujeito histórico, com sua vida particular, em família, seus interesses legítimos, seus negócios privados, sua consciência moral, sua formação cultural etc. No entanto, sua essência livre só se torna

\footnotetext{
12 Lembramos a análise crítica de Bernard Bourgeois sobre essa questão em seu artigo "Hegel: de la reconnaissance à l'intégration", no qual afirma: "A vida no Estado-Nação não é construída sobre o reconhecimento como ligação horizontal, intersubjetiva ou interativa, mas sobre a integração - ligação vertical - ao todo". In: RAISONS POLITIQUES. Revue de théorie politique. La reconnaissance: lectures hégéliennes, Fév./2016, n.61, p.45.

13 Para um aprofundamento da noção de essência em Hegel, ver SALGADO, 1996, p.127-157.
} 
algo efetivo, objetivo, se ele se sabe livre e se reconhece membro de uma comunidade constituída em vista da realização da liberdade de todos e tem nela uma atividade voltada para a concretização desse fim universal. Ambos, Estado e cidadãos, estão, portanto, inseridos numa relação dinâmica da qual emerge a "identidade substancial do gênero" (HEGEL, 1981, p.202) - o mundo ético - que determina conceitualmente um e outro: no Estado, são as regras da justiça, suas instituições e leis; no cidadão, é sua consciência e seu querer mais elevado.

\section{Referências}

ARENDT, H. Condition de l'homme moderne. Traduit de l'anglais (Etats-Unis) par Georges Fradier. Paris: Calmann-Lévy/Pocket, 1983 [coll. «Agora»].

BOURGEOIS, B. “Hegel: de la reconnaissance à l'intégration". In: Raisons Politiques. Revue de théorie politique. La reconnaissance: lectures hégéliennes, n.61, Fév./2016.

FLEISCHMANN, E. La philosophie politique de Hegel: sous forme d'un commentaire des Fondements de la philosophie du Droit. Paris: Librairie Plon, 1964.

. La Science universelle ou la Logique de Hegel. Paris: Librairie Plon, 1968.

GRANDJEAN, A. "Hegel et l' "équivoque" de la conscience moral”. In: Hegel penseur du droit, sous la direction de Jean-François Kervégan et Gilles Marmasse. Paris: CNRS, 2004.

HEGEL, G. W. Linhas Fundamentais da Filosofia do Direito ou Direito Natural e Ciência do Estado em Compêndio. Trad. Paulo Meneses, Agemir Bavaresco, Alfredo Moraes, Danilo Vaz-Curado R. M. Costa, Greice Ane Barbieri e Paulo Roberto Konzen. 2. ed. São Leopoldo: UNISINOS/Loyola, 2010. Coleção Ideias.

Principes de la Philosophie du Droit. Traduit et commenté par JeanFrançois Kervégan. Paris: PUF/Quadrige, 1998. Phénoménologie de l'Esprit. Tome I. Traduction et notes par Jean Hyppolite. Paris: Aubier, 1941.

. Science de la Logique: la logique subjective ou doctrine du concept.

Deuxième tome. Traduction, présentation et notes par Pierre-Jean Labarrière et Gwendoline Jarczyk. Paris: Aubier, 1981. 
Enciclopédia das ciências filosóficas em compêndio (1830). Tradução Paulo

Meneses. São Paulo : Loyola, 1995. v. III, A filosofia do espírito.

Encyclopédie des Sciences philosophiques en abrégé. Traduit par Maurice de

Gandillac. Paris: Gallimard, 1970.

HONNETH, A. La lutte pour la reconnaissance. Traduit de l'allemand par Pierre Rusch. Paris: CERF, 2010.

. Les pathologies de la liberté: une réactualisation de la philosophie du droit de

Hegel. Traduction de Franck Fischbach. Paris: La Découverte, 2008.

. Le droit de la liberté: esquisse d'une éthicité démocratique. Traduit

de l'allemand par Frédéric Joly et Pierre Rusch. Paris: Gallimard, 2015.

JARCZYK, G.; LABARRIERE, P. -J. Hegeliana. Paris: PUF, 1986 [coll.

«Philosophie d'aujourd'hui»).

KANT, E. Fondements de la métaphysique des mours. Traduction, notes et postface par Victor Delbos. Préface de Monique Castillo. Paris: Le livre de poche, 1993. . Paix perpétuelle. Traduction Darbellay. Paris: PUF, 1974.

LEFEBVRE, H. Lógica formal, lógica dialéctica. Traducción de M. Esther Benitez Eiroa. Madrid: Siglo XXI de España, 1970.

LIMA VAZ, H. C. Escritos de Filosofia II: ética e cultura. $2^{e}$ ed. São Paulo: Loyola, 1993.

MARCUSE, H. Razãa e revolução: Hegel e o advento da teoria social. 4. ed. Rio de Janeiro: Paz e Terra, 1988.

PIPPIN, R. "Rationalité et priorité de la vie éthique selon Hegel”. In: Revue Germanique Internationale, Hegel: droit, histoire, société. Paris: PUF, n.15, 2001.

RICOEUR, P. O si mesmo como um outro. Campinas: Papirus, 1991.

ROSENFIELD, D. Politique et liberté: une étude sur la structure logique de la Philosophie du droit de Hegel. Paris: Aubier, 1984 [coll. «Philosophie de l'Esprit»].

SALGADO, J. C. A Ideia de Justica em Hegel. São Paulo: Loyola, 1996.

SAINT AUGUSTIN. Confessions. Traduction d'Arnauld d'Andilly. Paris:

Gallimard, 1993, n.2465 [coll. «Folio Classique»].

TINLAND, O. La reconnaissance: par les mours ou par les institutions?: Hegel relu par Honneth. La Vie des idées, 14/11/2008. Disponível em: 
$<$ http://www.laviedesidees.fr/La-reconnaissance-par-les-moeurs.html $>$. Acesso em: 12/04/2016.

WEIL, E. Hegel et l'Etat: cinq conférences. $2^{\mathrm{e}}$ éd. Paris: Librairie Philosophique J. Vrin, 1966.

Filosofia política. Tradução Marcelo Perine. São Paulo: Loyola, 1990.

E-mail: dela.savia@mac.com

Recebido em: 02/2016

Aprovado em: 09/2017 